\title{
Políticas públicas para o desenvolvimento local: o caso de fomento às indústrias de móveis de Guarapuava, Paraná
}

Public policy for the local development: the case of incentive to the furniture industries of Guarapuava, Paraná

Políticas públicas para el desarrollo local: el caso para alentar a las industrias de muebles en Guarapuava, Paraná

Politiques publiques pour le développement local: le cas d'encouragement aux industries de meubles de Guarapuava, de Paraná

\author{
Geverson Grzeszczeszyn* \\ Hilka Pelizza Vier Machado**
}

Recebido em 3/7/2009; revisado e aprovado em 12/12/2009; aceito em 15/2/2010

\begin{abstract}
Resumo: Este estudo analisa as políticas públicas para o desenvolvimento local, tendo como base o caso das indústrias de móveis da cidade de Guarapuava, no estado do Paraná. Trata-se de pesquisa qualitativa e o principal resultado do estudo indica que não houve a consecução dos resultados planejados pelas políticas públicas que foram formuladas reiteradamente por cada gestão municipal, desde a década de 1980, na cidade.

Palavras-chave : Desenvolvimento local. Políticas públicas. Indústria moveleira.

Abstract: This study analyzes the public policy for the local development, tends as base the case of the furniture industries of the city of Guarapuava, in the state of Paraná. It is treated of qualitative research and the principal result of the study indicates that there was not the attainment of the results planned by the public policy, that repeatedly were formulated by each public administration, since the decade of 1980, in the city.

Key-words: Local development. Public policy. Furniture industry.

Résumé: Cette étude analyse les politiques publiques pour le développement local, dans le cas des industries de meubles de la ville de Guarapuava, au Paraná, Brésil. Il s'agit de une recherche qualitative et le principal résultat de l'étude est qu'il n'a pas y eu la conquête des résultats prévus par les politiques publiques, qui ont été formulées à chaque gestion municipale, depuis la décennie de 1980.

Mots-clés: Développement local. Politiques publiques. Industrie de meubles.

Resumen: Este estudio examina las políticas públicas para el desarrollo local, basado en el caso de las industrias de muebles de la ciudad de Guarapuava, Provincia del Paraná. Esta es una investigación cualitativa y el principal resultado del estudio indica que fue el logro de los resultados previstos por las políticas públicas, que se han hecho en repetidas ocasiones por cada gestión municipal, desde el decenio de 1980 en la ciudad.

Palabras clave : Desarrollo local. Políticas públicas. Industria de muebles.
\end{abstract}

\section{Introdução}

O desenvolvimento local é fundamentado no protagonismo da sociedade, ou seja, na participação da comunidade (pessoas e organizações) como construtora do seu destino. Assim, articulam-se os atores sociais pessoas, organizações/instituições e poder público em torno das potencialidades locais. Nesse processo, fatores como capital social, capital humano, redes sociais, organização popular, políticas públicas, educação, cooperação, negociação e solidariedade são ele- mentos-chaves para a promoção da dinâmica transformadora local.

Este trabalho tem como objetivo principal analisar as políticas públicas de apoio e fomento ao setor da indústria de móveis da cidade de Guarapuava, no Paraná, tendo em vista a existência em abundância de matéria-prima - a madeira - na cidade e região. A Prefeitura Municipal, por meio de políticas públicas, desde a década de 1980, vem estimulando a produção de móveis em série e o trabalho conjunto entre empresários do setor. A cidade possui diversas marcena-

\footnotetext{
* Professor de Administração da Universidade Estadual do Centro-Oeste (UNICENTRO), Guarapuava, PR. Mestre em Administração pela Universidade Estadual de Maringá (UEM). Doutorando em Administração pela Universidade Federal do Paraná (UFPR). E-mail: geverson@ymail.com

** Professora do Programa de Pós-Graduação - Mestrado em Administração, da UEM. Doutora em Engenharia da Produção pela Universidade Federal de Santa Catarina (UFSC). E-mail: hilkavier@yahoo.com
} 
rias, em torno de quarenta, que produzem móveis sob medida, num sistema de produção quase artesanal. Atualmente, existem apenas duas indústrias que produzem móveis totalmente no modelo de produção em série, destacando-se uma delas, de médio porte, que vende móveis para todo o Brasil, em especial os do tipo beliche.

A pesquisa foi realizada por meio de entrevistas em profundidade com o Secretário de Indústria e Comércio e dois ex-Secretários de Indústria e Comércio da cidade de Guarapuava-PR. Foram entrevistados ainda três ex-empresários moveleiros e mais dez empresários com empresas ativas no mercado, totalizando dezesseis participantes.

A seguir, apresentam-se considerações teóricas sobre as políticas públicas para o desenvolvimento local. Em seguida, são detalhados os procedimentos metodológicos. Posteriormente, são apresentados e analisados os resultados da pesquisa e, por fim, as considerações finais.

\section{Políticas públicas e desenvolvimento local}

Existem cada vez mais conexões da sociedade civil com o Estado e também com o mercado, na forma de múltiplas parcerias intersetoriais. Isso está acontecendo independentemente da vontade dos atores sociais e empresariais e do sistema político, em função da dinâmica da rede social. Quanto mais se entretece essa rede, quanto mais a sociedade vai adquirindo a morfologia e a dinâmica de rede, mais canais de participação, mais caminhos de cooperação entre os diversos tipos de agenciamento vão sendo ativados ou trafegados (FRANCO, 2006a). Diante dessa realidade, o setor público assume um papel fundamental como estimulador das inovações, tão fundamentais para um processo de desenvolvimento local. Assim, as condições locais culturais, econômicas e sociais representam uma variável essencial para a efetiva capacidade de inovação, por absorver os novos paradigmas para o desenvolvimento econômico (MARTINELLI; JOYAL, 2004).

Embora a participação de diferentes atores sociais esteja sendo estimulada, "[...] o Estado deve assumir suas funções essenciais, que são indelegáveis. Não pode sim- plesmente repassar para a sociedade resolver, pois o custo da estrutura montada acaba ficando mais caro do que se tivesse isso internalizado dentro do Estado" (FISCHER, 2006, on line). Por isso mesmo, entre outras razões, ao se analisarem experiências de desenvolvimento local/regional, vê-se reforçada a noção de que a presença do Estado é fundamental (BARBOSA et al., 2004). No entanto, convém frisar que a tendência é o Estado tornar-se menos intervencionista, com sua atuação voltada para a orientação da economia. Souza (2005) considera que essa coordenação pode ser constituída pela montagem de um banco de projetos em áreas de interesse estratégico e pela busca de grupos privados interessados na realização de empreendimentos conjuntos. Assim, o enfraquecimento do Estado-nação gerado pela globalização cria a necessidade de que as cidades assumam um papel mais independente na formulação e implantação de seu processo de desenvolvimento e acumulação de riquezas (LOPES, 1998).

Com isso, orientações estratégicas e diretrizes do poder público expressam as mais diversas políticas públicas (econômicas, sociais, ambientais, educacionais e outras), que podem influir no processo do desenvolvimento local. Para se compreender melhor a função de uma política pública, Ferreira (1987) recorre a uma analogia com cada organismo vivo do corpo social que se rege por uma política, isto é, por uma maneira de se comportar, de conquistar a prosperidade. No processo de construção e definição de políticas públicas é importante mencionar que cada localidade possui uma cultura peculiar, uma história socioeconômica e, por isso, as concepções de políticas públicas devem ser adequadas a diferentes realidades (MATA, 2007). Várias são as possibilidades metodológicas para que o processo de interação "sociedade-poder público" possa vir ao encontro das necessidades de um lugar (TENÓRIO; DUTRA; MAGALHÃES, 2004). São as políticas públicas que estabelecem a conexão entre a sociedade civil e o poder público, haja vista que as políticas interferem, de forma inevitável, na conformação da dinâmica socioeconômica local. As políticas públicas são a base para a materialização dos objetivos do poder público perante a sociedade. 
Nesse contexto, a ação estratégica para que as próprias comunidades conheçam o que são e o que têm, e com base nisso e em sua capacidade metabolizadora de fatores externos se desenvolvam "de dentro para fora" implica mudança da cultura desenvolvimentista: requerendo clareza de intenções, coragem de "remar contra a maré" político-econômica mundialmente vigente e, sobretudo, perspicácia, pertinácia, competência e habilidade de influir sem impingir, de ajudar sem forçar e, enfim, de "contaminar a comunidade" para que paulatina e processualmente conquiste a capacidade da permanente construção do autodesenvolvimento. Ademais, pessoas, equipes, organizações e instituições que pretendam se dedicar à práxis do desenvolvimento local precisam também se desenvolver individualmente (ÁVILA, 2000).

Outro aspecto, vinculado às políticas públicas para o desenvolvimento local, está relacionado à provisão de recursos necessários para a execução dos projetos oriundos das iniciativas da comunidade. Na visão de González (2000) é desejável que o poder público apresente capacidade de financiamento dos projetos de desenvolvimento local. Entretanto, Franco (2006b), ao refletir sobre instâncias mais elevadas de poder público, defende que é um retrocesso vender a idéia, ilusória, de que se o desenvolvimento local for "promovido" à condição de política governamental federal terá mais condições de florescer porquanto terá verbas orçamentárias asseguradas. Para o autor, se tais recursos ficam disponíveis em alguma instância centralizada - nem que seja para o apoio a projetos que se enquadrem em determinados critérios - então a criatividade das populações envolvidas em um processo de desenvolvimento será trocada pela esperteza em navegar nos meandros político-burocráticos, muitas vezes clientelistas, para conseguir acessar o balcão.

Mas, assim como o desenvolvimento local precisa de políticas adequadas ao seu estímulo, o poder público também necessita de condições estruturais favoráveis para que as políticas públicas de indução do desenvolvimento local sejam efetivas. A burocracia apresenta-se como um entrave para os processos processos de desenvolvimento local, não assegurando que o serviço público signifique, na prática, servir ao público (DESBUROCRATIZAÇÃO..., 2004). Fischer (2006) menciona também que o governo não dialoga entre si e falta articulação governamental entre as esferas municipal, estadual e federal.

Diante desse cenário, há alternativas diferentes de atuação para o papel do setor público como agente facilitador na promoção do desenvolvimento econômico local. Esse papel pode ser o de focar nos objetivos econômicos locais, ligado simplesmente à criação de novos empregos e empresas ou ser um compromisso de prioridades e recursos para o desenvolvimento de empresas já existentes, com aperfeiçoamento da qualidade de produção e da capacidade tecnológica local. E pode, ainda, ser um enfoque proativo e preventivo para a economia do lugar, em busca de novas oportunidades de desenvolvimento dentro dos interesses e das vocações da comunidade local (MARTINELLI; JOYAL, 2004).

Dois tipos de políticas públicas se destacam para a promoção do desenvolvimento local: as políticas públicas para as empresas e as políticas públicas educacionais. No entanto, tendo em vista que o desenvolvimento local visa promover a melhoria da qualidade de vida do local, não se pode prescindir das demais políticas. Mesmo porque, conforme lembra González (2000, p. 10),

[...] é necessário ter em mente que o desenvolvimento local implica uma perspectiva integral que precisa estar, necessariamente, apoiada nas diferentes políticas setoriais.

No campo empresarial, são os pequenos empreendimentos os que com maior rapidez e eficiência podem absorver o imenso contingente de trabalhadores (GUERRA, 1997) e impulsionar o desenvolvimento local. O setor público pode atuar como facilitador de atividades para qualificar, treinar e desenvolver as pessoas, gerando, por conseguinte, condições para o processo de desenvolvimento local (MARTINELLI; JOYAL, 2004).

Dessa forma, desenvolvimento e educação andam juntos. As políticas públicas de apoio, estímulo e manutenção das escolas e universidades são fatores fundamentais para o desenvolvimento local. Entretanto, não se trata apenas da educação oficial 
oferecida pelos bancos de escolas e universidades, que é imprescindível, mas também de se criar um ambiente propício para a estruturação de outras instituições e mecanismos de formação (política, cultural, profissional, etc.) à sociedade, no sentido de constantemente agregar competências, habilidades e conhecimentos à população, aumentando o capital humano.

Uma comunidade informada e inteligente, que compartilha conhecimento, constitui um fator favorável ao surgimento de vários processos como: a aprendizagem coletiva, a inovação, a transformação em uma região que aprende, ao mesmo tempo inteligente e voltada à cooperação. A criação da sinergia coletiva a partir do conhecimento distribuído gera, através do consenso, o poder necessário para pôr em prática propostas de desenvolvimento cuja audácia inovadora deve ser uma função inversa ao grau de atraso do território. Atualmente, o desenvolvimento de um território não é feito pelos tecnocratas, nem pelos burocratas e nem os políticos. Quem faz o desenvolvimento é a "gente", as pessoas que "pisam a terra" diariamente, que tem conhecimento sobre o local onde vivem, que sentem cotidianamente que o progresso está ali, mas que lhes escapa (BOISIER, 2001).

Dowbor (2006) lembra ainda a importância de os indivíduos receberem educação também sobre a realidade local, em todos os sentidos, haja vista que o desenvolvimento moderno necessita cada vez mais de pessoas informadas sobre a realidade onde vivem e trabalham.

\section{Aspectos metodológicos}

Para a realização desta pesquisa, que teve como principal objetivo analisar as políticas públicas para a promoção do desenvolvimento local, tendo como foco empresas do setor industrial moveleiro de Guarapuava-PR, utilizou-se a abordagem qualitativa, que conforme Bauer e Gaskel (2000) tem a finalidade real de explorar o espectro de opiniões, as diferentes representações sobre o assunto em questão. O estudo foi subdividido em três fases.

Na primeira fase foram entrevistados empresários de empresas que estão em funcionamento. O conjunto de sujeitos da pesquisa foi composto por dez empresários da indústria moveleira da cidade de Guarapuava-PR (há em torno de 40 indústrias). Dois critérios foram usados para a seleção dos empresários. O primeiro foi a idade da empresa, privilegiando aqueles empresários com maior tempo de atuação no município. Acredita-se que o tempo de existência da empresa é um fator relacionado à capacidade de apresentar um conjunto de informações adequadas para a consecução dos objetivos da pesquisa. Adicionalmente, outro critério utilizado foi o porte da empresa, mensurado por meio do número de funcionários. Foram selecionados micros, pequenas e médias empresas da indústria moveleira, sendo que não há indústria moveleira de grande porte na cidade.

$\mathrm{Na}$ segunda fase, foram entrevistados empresários de empresas que não estão mais em funcionamento. O conjunto de sujeitos da pesquisa, nesta fase, foi composto por três ex-empresários da indústria moveleira da cidade de Guarapuava-PR.

$\mathrm{Na}$ terceira fase foram entrevistados o atual secretário de Indústria e Comércio de Guarapuava, e mais dois ex-secretários para identificar as políticas públicas para o setor moveleiro, bem como verificar as dificuldades de implantação dessas políticas entre os empresários moveleiros. A técnica de coleta de dados nesta etapa da pesquisa foi a entrevista semiestruturada. Nela o entrevistador fica livre para exercitar sua iniciativa no acompanhamento da resposta a uma pergunta e pode fazer perguntas relacionadas que não foram previamente imaginadas (HAIR JR. et al., 2005). Foram utilizados dois roteiros de questões: um para os empresários e outro para os representantes do poder público municipal. Ao todo, foram realizadas dezesseis entrevistas. Após a transcrição de cada entrevista, o texto foi enviado ao entrevistado para confirmação do conteúdo. Se o entrevistado julgasse necessário, eram feitas alterações e novamente enviadas ao entrevistado, para que não houvesse dúvidas ou incertezas sobre o conteúdo do discurso colhido e registrado. Este processo é caracterizado como critério de "validação comunicativa" em pesquisa qualitativa (BAUER; GASKELL, 2000). Todas as entrevistas foram validadas pelos participantes. 
A análise dos dados ocorreu mediante uso da técnica denominada "análise de conteúdo". Conforme Bardin (2004, p. 37), a análise de conteúdo é um conjunto de técnicas de análise das comunicações visando obter, por meio de procedimentos sistemáticos e objetivos de descrição do conteúdo das mensagens, indicadores (quantitativos ou não) que permitam a inferência de conhecimentos relativos às condições de produção/ recepção (variáveis inferidas) dessas mensagens. Trata-se de compreender melhor um discurso, de aprofundar suas características (gramaticais, fonológicas, cognitivas, ideológicas etc.) e extrair os momentos mais importantes (RICHARDSON, 1999).

O quadro 1 apresenta o perfil das empresas cujos empresários foram entrevistados.

\begin{tabular}{|c|c|c|c|c|}
\hline $\begin{array}{c}\text { Início de } \\
\text { operação }\end{array}$ & $\begin{array}{c}\text { Quantidade } \\
\text { proprietários }\end{array}$ & $\begin{array}{c}\text { Quantidade } \\
\text { Empregados }\end{array}$ & $\begin{array}{c}\text { Modelo } \\
\text { produção }\end{array}$ & Critério de seleção \\
\hline 2003 & 8 & 50 & Série & Nr. empregados \\
\hline 1987 & 1 & 7 & Sob medida & Tempo de atuação \\
\hline 1987 & 1 & 3 & Sob medida & Tempo de atuação \\
\hline 1982 & 1 & 6 & Sob medida & Tempo de atuação \\
\hline 1976 & 2 & 5 & Sob medida & Tempo de atuação \\
\hline 1975 & 3 & 100 & Série & Tempo de atuação e n. empregados \\
\hline 1970 & 1 & 5 & Sob medida & Tempo de atuação \\
\hline 1964 & 2 & 25 & Ambos & Tempo de atuação e n. Empregados \\
\hline 1960 & 4 & 6 & Sob medida & Tempo de atuação \\
\hline 1955 & 3 & 4 & Sob medida & Tempo de atuação \\
\hline
\end{tabular}

Quadro 1 - Perfil de empresas de empresários entrevistados (empresas ativas)

Como já mencionado e ilustrado no quadro 1, buscou-se uma heterogeneidade entre as empresas, tanto em termos de porte, como de idade. A seguir, são tecidas considerações relacionadas aos resultados do estudo.

\section{Apresentação e análise dos resultados}

Tendo em vista a relevância da cadeia produtiva da madeira para a cidade de Guarapuava e região em função da disponibilidade de matéria-prima - a madeira - foram realizadas diversas tentativas, desde o final da década de 1980, de se estruturar a produção de móveis em série e de se realizar trabalho conjunto entre empresários do setor moveleiro.

Desde então, tais tentativas de organização do setor vêm sendo renovadas pelos diferentes grupos políticos que assumiram o poder público municipal. O principal objetivo dos projetos públicos era, e ainda é, estimular a produção de móveis em série pelos empresários, e, paralelamente a esse processo, promover união, associativismo, colabo- ração e parcerias de negócios entre empresários moveleiros de forma que a classe viesse a se fortalecer no mercado, contribuindo, de diversas formas, para o desenvolvimento da cidade.

Entretanto, o modelo de produção sob medida predomina entre os marceneiros. Existem apenas duas indústrias focadas totalmente no modelo de produção de móveis em série. Estas empresas são as maiores indústrias moveleiras, em número de empregados, da cidade. Apresenta-se, a seguir, interpretações de representantes do poder público municipal sobre políticas públicas criadas para o setor moveleiro, bem como de empresários e ex-empresários da indústria moveleira.

\subsection{Políticas públicas: décadas de $\mathbf{1 9 8 0}$ e 1990}

No final da década de 1980, foi criado pelo poder público municipal um projeto de política industrial, de forma geral, para a cidade. A intenção foi proporcionar apoio aos empresários moveleiros, marceneiros, 
para que, gradativamente, pudessem tornarse fabricantes de móveis em série. Na época, não havia indústria moveleira na cidade que produzisse sob o modelo de produção de móveis em série. O principal motivo para a criação de políticas públicas para o setor moveleiro, na época, era a existência de matéria-prima principal para a produção de móveis - a madeira - em Guarapuava e região.

Foram realizadas reuniões com empresários moveleiros, com a diretoria da Associação Comercial da cidade e ainda com o pessoal da Secretaria de Indústria e Comércio, sendo que uma das iniciativas era fazer uma cooperativa de compra de matéria-prima entre os empresários moveleiros.

Porém, nessa tentativa de estruturação do setor existiram dificuldades na implementação de iniciativas públicas, como o fato de que parte da sociedade interpretou tais projetos públicos como sendo algo temporário, sem continuidade, apenas de interesse político. Outros fatores como a desunião entre lideranças da sociedade e entre a classe de marceneiros foram elementos que influíram nos resultados das iniciativas públicas da época.

Uma das causas de certa desunião entre empresários era a falta de mão-de-obra para o setor moveleiro. Assim, quando um profissional tornava-se marceneiro, por meio do trabalho numa marcenaria, era disputado por outras marcenarias, que precisavam de profissionais preparados. O problema de falta de profissionais seria sanado com parceria entre a prefeitura e o SENAI, que proporcionaria a formação de mão-de-obra.

Observe-se que as marcenarias que produzem móveis sob medida dependem de profissionais - marceneiros - formados, experientes, que conheçam todo o processo de produção, que sejam praticamente artesãos, devido às peculiaridades de cada móvel a ser fabricado. Essa dependência não ocorre no modelo de produção em série.

Nesse contexto, existiram também barreiras políticas que prejudicaram o andamento do projeto, que tinha como alvo os pequenos empresários da indústria de móveis. Houve dificuldade de articulação entre instituições que poderiam ter sido parceiras na promoção de projeto público para a indústria moveleira. Outra dificuldade constatada foi a existência de grupo político de oposição, na cidade, que atuava no sentido de conquistar o poder, haja vista que era um período de fim de mandato político.

A mudança de poder político na prefeitura pode significar descontinuidade de políticas públicas. Esse fato foi observado por empresários moveleiros como um obstáculo para o desenvolvimento do setor, haja vista que, desde a década de 1980, o poder público municipal tenta alavancar o setor moveleiro estimulando a produção de móveis em série.

Destaque-se ainda que essa descontinuidade de políticas públicas é facilitada pela desarticulação da classe empresarial moveleira existente na cidade, apontada pelos próprios empresários. A falta de continuidade também pode estar aliada ao fato de lideranças de projetos públicos não conhecerem com profundidade o setor moveleiro, o que faz com que empresários envolvidos vejam isso como uma falha. Talvez a busca de envolvimento maior de empresários moveleiros na concepção de políticas e projetos públicos seja um fator para evitar esse problema, conforme destacou um empresário do setor.

Outro agravante para o êxito do projeto público de estímulo ao setor moveleiro foi o fato de se terem envolvidas, no projeto, categorias empresariais que não eram da indústria de móveis, apesar de fazerem parte da cadeia produtiva da madeira. Logo, por serem classes empresariais diferentes, os interesses eram diferentes também, o que prejudicava o processo de articulação do setor com a consequente criação de uma associação dos empresários, conforme descreveu um ex-empresário da época.

Foram mencionados também problemas gerados por diferenças de porte entre as empresas participantes, pois os empresários moveleiros, na época, eram, em geral, pequenas marcenarias. Os empresários de grande porte estavam liderando o processo, o que afastou os pequenos marceneiros, que representavam a maioria no projeto. Esse fato dificultou a consolidação de trabalho conjunto entre empresários, segundo relato de um empresário.

Destaque-se ainda que muitos marceneiros não possuíam formação gerencial e 
não percebiam as oportunidades de mercado que a produção de móveis em série poderia gerar. Além disso, havia expectativas equivocadas por parte de empresários moveleiros de que a prefeitura daria dinheiro aos empresários.

Deste modo, devido às dificuldades e obstáculos descritos, o projeto de estímulo e apoio à produção de móveis em série na cidade não teve continuidade:

Não avançamos nada, não avançamos nada, não. Na verdade, o pessoal não demonstrou qualquer interesse em continuidade do assunto. Nós tínhamos interesse em formar [...] os empresários do setor [...] eles não [...] não valorizaram a iniciativa do poder público, na verdade. Não deu. (Secretário de Indústria e Comércio da época).

Apesar disso, identificou-se nos relatos que uma indústria de móveis sob medida, na época, foi estimulada e apoiada para transformar-se em empresa de produção em série, obtendo inclusive apoio estrutural por meio da concessão de terreno pelo poder público. Atualmente essa indústria tem atuação destacada no setor moveleiro, em nível nacional.

\subsection{Políticas públicas: período de 2001 a 2004}

Nesse período, tendo em vista a importância da cadeia produtiva da madeira, identificaram-se políticas voltadas à criação de uma escola de marcenaria para atender uma das principais reclamações de marceneiros, que era a falta de mão-de-obra qualificada. Esta seria uma fase inicial de um projeto que teria continuidade, no sentido de alavancar o setor moveleiro na cidade, estimulando, posteriormente, a produção de móveis em série e a cooperação entre os empresários. $\mathrm{O}$ objetivo do poder público era despertar uma atitude de cooperação entre industriais moveleiros, estimulando a fabricação de móveis em série para o mercado globalizado e não apenas local, que é uma característica das marcenarias, com o modelo de produção sob medida.

Nesse contexto, tendo em vista as dificuldades estruturais e de segurança para a prefeitura criar essa escola e visando alcançar esse objetivo, buscaram-se parceiros, especialistas em educação industrial. Realizou-se, então, reunião com representantes do SENAI (Serviço Nacional de Aprendizagem Industrial) e da FIEP (Federação das Indústrias do Estado do Paraná). Articularam-se parcerias entre SENAI, FIEP e prefeitura, para estruturar essa escola de marcenaria que proporcionaria qualificação de mão-de-obra para a indústria moveleira.

Tratava-se de se oferecer curso para quinze a vinte pessoas, focado na indústria moveleira e profissionalizante, de longa duração. Procedeu-se, então, à negociação de custos do projeto entre as entidades parceiras. Porém, apesar da falta de mão-de-obra ser uma reclamação de marceneiros, ocorreu um fato imprevisto no processo de execução do projeto da escola de marcenaria, ou seja, num primeiro momento, não houve inscrições para o curso. Ficou evidente a preocupação de marceneiros com a qualificação de seu pessoal e a preocupação que eles deixariam a empresa depois de qualificados para abrirem suas próprias marcenarias.

Além disso, havia interesses particulares de representantes da classe empresarial moveleira, no processo de criação da escola de marcenaria, que se sobreponham aos interesses coletivos, mais especificamente, havia marceneiros que queriam ser os professores dessa escola, vendo a escola de marcenaria mais como uma oportunidade de trabalho para eles próprios. Apesar disso, foi oferecida uma turma do curso.

Outra dificuldade para a promoção de políticas públicas para o setor moveleiro foi também a falta de união e liderança entre os marceneiros. A prefeitura promoveu viagens para polos moveleiros, como Arapongas-PR, com a intenção de apresentar outras realidades da indústria moveleira e estimular a produção de móveis em série, mas havia dificuldade em conseguir a participação de empresários que apresentavam como argumento, principalmente, a falta de tempo.

A FIEP promoveu a MOPI-Mostra de Produtos Industrializados de Guarapuava, com o apoio do poder público e outras instituições da cidade, mas houve dificuldade de conseguir a participação de marceneiros. Segundo o poder público municipal, apesar da divulgação do evento, apenas a maior indústria de móveis da cidade, com processo 
de produção em série, participou de todas as edições da MOPI. Entretanto, um marceneiro que participou de uma edição dessa feira reclamou da falta de divulgação dela entre os empresários moveleiros.

Havia também barreiras políticas nessa época que prejudicaram as políticas públicas de estímulo ao setor moveleiro, em função de disputas de grupos políticos. Conforme destaca o ex-Secretário de Indústria e Comércio deste período:

Tem forças que querem desenvolvimento, querem o capital humano, querem uma educação melhor para Guarapuava e querem tudo de bom para Guarapuava. Agora, existem forças ocultas que não querem. E, coincidentemente, esses grupos são identificados em grupos políticos.

A cultura de empresários focada no processo de produção de móveis sob medida foi outro fator que contribuiu para dificultar a efetivação de políticas públicas para o setor nesse período, haja vista que o processo de produção de móveis em série exige mudanças na forma de gestão e organização da empresa. Esse fato foi enfatizado tanto pelo poder público quanto por empresários que participaram do projeto, os quais também comentaram sobre o baixo nível educacional dos marceneiros e a descontinuidade de projetos públicos para se criar o polo moveleiro na cidade.

\subsection{Políticas vigentes}

Atualmente, existem políticas públicas para o setor moveleiro que visam alavancar o setor. Os objetivos principais do projeto não são diferentes dos demais já executados por gestões municipais anteriores. A intenção continua sendo a promoção da produção de móveis em série e do trabalho conjunto entre os empresários moveleiros, a partir da transformação de marcenarias que produzem móveis sob medida em indústrias com o modelo de produção em série.

O poder público municipal possui duas referências principais que alicerçam o projeto. Uma delas é uma empresa fabricante de móveis sob o modelo de produção em série, de Guarapuava, que é considerada um exemplo a ser seguido pelos demais marceneiros, haja vista que essa empresa já foi uma pequena marcenaria. A outra referência importante para a criação do projeto público atual é o polo moveleiro da cidade de Arapongas-PR. Destaque-se também que a existência de matéria-prima na cidade de Guarapuava e região para a produção de móveis - a madeira - (que inclusive é vendida para as indústrias do polo de Arapongas), foi um fator determinante para o estabelecimento de políticas públicas para o setor moveleiro. O projeto iniciou em 2005, com o envolvimento de aproximadamente 40 marceneiros. Atualmente, somente uma dezena deles continua no projeto. Os marceneiros participaram de cursos de formação gerencial e técnica no SEBRAE, SESI e no Centro de Treinamento da Madeira do polo moveleiro de Arapongas. A prefeitura quer despertar o "espírito empreendedor" dos pequenos empresários.

Espera-se assim que, a partir do momento emque os empresários participantes do projeto estiverem produzindo móveis em série, tornem-se exemplos a serem seguidos pelos demais. Para isso, o poder público municipal adquiriu, em 2007, máquinas de produção de móveis, no valor inicial de $\mathrm{R} \$ 300.000,00$, para estruturar marcenarias e definiu as estratégias gerais de como irá funcionar essa parceria entre a prefeitura e os marceneiros. Parte das máquinas encontram-se com os marceneiros, por meio de comodato.

Os modelos de móveis a serem produzidos pelos participantes do projeto estão definidos e a produção será realizada por meio de parcerias de negócios entre os empresários, pois cada um produzirá, em série, partes de móveis, as quais formarão o móvel final. Nessa sistemática, os marceneiros terão que atuar em conjunto, dialogando e negociando em equipe.

Foram realizadas reuniões entre a prefeitura e os empresários moveleiros, nas quais o objetivo era a discussão de aspectos sobre o funcionamento do negócio em parceria, resultado do projeto, além da promoção de formação gerencial de marceneiros, haja vista que o processo de produção de móveis em série é diferente do processo sob medida.

No entanto, apesar do projeto estar em andamento, há dúvidas de participantes 
sobre os detalhes de como irá funcionar o sistema de produção em parceria entre os empresários estimulado pelo poder público municipal. Mais especificamente, processos organizacionais importantes como a venda da produção e a compra de matéria-prima são aspectos do projeto que ainda não estão esclarecidos, conforme expressou um empresário que participa do projeto público. Alguns empresários desconhecem quem está à frente do projeto, sendo que um deles mencionou o SEBRAE, enquanto que, de fato, é a prefeitura municipal.

Um dos empresários informou que não tem conhecimento de políticas públicas atuais do poder público municipal, mas que, há aproximadamente dez anos, participou de reuniões no SESI, com outros moveleiros. O objetivo, naquela época, era unir os empresários moveleiros para produzir em série, mas, segundo ele, essa idéia da prefeitura e de alguns moveleiros não deu certo. Outro entrevistado ainda ficou sabendo do projeto atual da prefeitura para o setor moveleiro quando o projeto já estava em andamento. Por isso, segundo ele, não participou.

A necessidade de formação gerencial é mencionada como uma condição mais importante até do que a questão financeira para a atuação do empresário moveleiro no modelo de produção em série, sendo que a falta de formação gerencial e técnica foi apontada também como motivo de desistência do projeto, haja vista que o próprio grupo de empresários excluía aqueles com pouca capacitação.

Por outro lado, as exigências do poder público em termos de disponibilização de tempo pelos integrantes do projeto para que participassem de atividades como cursos, viagens, feiras e reuniões também foi um motivo de desistência do projeto, além de descrédito nas políticas públicas. Outras dificuldades ou obstáculos verificados no processo de execução de iniciativas públicas municipais para o setor moveleiro foram: a cultura voltada à produção de móveis sob medida, mantida, principalmente, pelos proprietários de marcenarias, haja vista que eram de empresas familiares, apesar de a prefeitura contatar os filhos de marceneiros, porque poderiam ser mais receptivos às novas idéias.
O fechamento de indústrias de móveis em série no polo moveleiro de Arapongas também influenciou a atitude de empresários marceneiros sobre o projeto. O julgamento por parte de marceneiros de que o projeto era apenas um ato passageiro e sem continuidade, foi também um obstáculo à participação. As tentativas frustradas de projetos anteriores contribuíram para a existência de atitudes de desconfiança de empresários em relação aos projetos.

Outro fator que afastou a participação de marceneiros no projeto atual foi a necessidade de investimentos em máquinas e capital de giro para a produção em série. Máquinas que exigiriam parte dos investimentos foram compradas pela prefeitura, mas há, agora, outro desafio a ser superado pelos empresários moveleiros integrantes do projeto, conforme eles mesmos descreveram: o investimento considerado elevado pelos marceneiros para a operacionalização da produção (estruturação de sistemas produtivos, capital de giro, compra de matériasprimas, etc.), além do consequente risco do negócio.

Entretanto, há projeções para que o setor moveleiro na cidade de Guarapuava transforme-se em um polo moveleiro a longo prazo. Haverá continuidade nas ações do projeto, sendo que a prefeitura pretende apoiar as empresas integrantes por meio de ações como: auxílio na criação de catálogos para distribuição, contatos com grandes redes de lojas, comercialização e participação em feiras. Outra preocupação expressada foi em relação à utilização sustentável da matéria-prima na cidade, pois a prefeitura possui um projeto em que estimula os pequenos agricultores a investir em reflorestamento.

\subsection{Síntese de fatores facilitadores e inibidores de políticas públicas ao setor moveleiro}

Em síntese, o quadro 2 apresenta os fatores facilitadores e inibidores de execução de políticas públicas ao setor moveleiro na cidade. 


\begin{tabular}{|c|c|}
\hline Fatores facilitadores & Fatores inibidores \\
\hline $\begin{array}{l}\text { - Existência de matéria-prima na cidade e } \\
\text { região: madeira. } \\
\text { - Existência de profissionais de marcenaria, } \\
\text { experientes em produção de móveis, mesmo } \\
\text { que sob medida. } \\
\text { - Existência de redes informais entre os } \\
\text { marceneiros da cidade, que proporcionam } \\
\text { trocas de conhecimentos e experiências sobre } \\
\text { o setor e máquinas, além de auxílios diversos. } \\
\text { - Existência de redes informais semelhantes } \\
\text { com marceneiros de outras cidades. } \\
\text { - Existência de parcerias de negócios entre } \\
\text { empresários moveleiros. } \\
\text { - Existência de parcerias de negócios entre } \\
\text { empresários moveleiros e outros ramos de } \\
\text { negócios. } \\
\text { - Articulação da prefeitura com instituições } \\
\text { como SEBRAE, SENAI, SESI, FIEP, e outros } \\
\text { centros de treinamento do ramo de móveis. } \\
\text { - Viagens a polos moveleiros. } \\
\text { - Viagens a feiras de máquinas e equipamentos } \\
\text { do setor. } \\
\text { - Apoio do poder público à feira de produtos } \\
\text { industrializados de Guarapuava: MOPI. } \\
\text { - Estruturação de escola de marcenaria. } \\
\text { - Aquisição, pelo poder público, de máquinas } \\
\text { para o setor moveleiro. } \\
\text { - Estruturação e oferecimento, por parte do } \\
\text { poder público e instituições, de cursos de } \\
\text { formação gerencial e técnicos para os } \\
\text { marceneiros. } \\
\text { - Filhos de marceneiros mais receptivos ao } \\
\text { - incentivos da prefeitura para que produtores } \\
\text { ruram em reflorestamento. }\end{array}$ & $\begin{array}{l}\text { - Falta de articulação entre lideranças de } \\
\text { instituições da cidade. } \\
\text { - Falta de união e associativismo entre a classe } \\
\text { de marceneiros. } \\
\text { - Falta de liderança na classe moveleira. } \\
\text { - Barreiras políticas, geradas por grupos de } \\
\text { oposição ao poder público. } \\
\text { - Falta de mão-de-obra qualificada para } \\
\text { produção em série. } \\
\text { - Personificação de ação institucional pública. } \\
\text { - Descontinuidade de políticas públicas a cada } \\
\text { gestão municipal, o que gera descrédito em } \\
\text { novas políticas. } \\
\text { - Envolvimento de categorias empresariais que } \\
\text { não eram da indústria de móveis. } \\
\text { - Diferenças de porte e de perfis de empresas } \\
\text { integrantes de projetos públicos. } \\
\text { - Valorização de grandes empresas em } \\
\text { detrimento de pequenas. } \\
\text { - Falta de formação gerencial e técnica de } \\
\text { empresários moveleiros. } \\
\text { - Expectativas de iniciativas públicas } \\
\text { paternalistas por parte de empresários. } \\
\text { - Falta de tempo de empresários para participar } \\
\text { de atividades de projetos públicos. } \\
\text { - Dificuldades de comunicação entre poder } \\
\text { público e empresários, pois há marceneiros que } \\
\text { desconhecem os projetos públicos para o setor. } \\
\text { - Cultura forte de produção de móveis sob } \\
\text { medida. } \\
\text { - Necessidade de capital e financiamento para } \\
\text { investimentos no modelo de produção em } \\
\text { - O risco de se iniciar um novo negócio baseado } \\
\text { no de produção em série. }\end{array}$ \\
\hline
\end{tabular}

Quadro 2 - Fatores facilitadores e inibidores de políticas públicas ao setor moveleiro com vistas ao desenvolvimento local

O quadro 2 sintetiza os principais pontos favoráveis e desfavoráveis à estruturação do setor moveleiro no município de Guarapuava, de acordo com os depoimentos dos participantes da pesquisa. Nota-se que há necessidade de estratégias que aproximem os pequenos empresários das diretrizes, orientações e discussões deflagradas por representantes públicos municipais, o que tem gerado uma continuidade de ações ao longo de três décadas, sem que um fortalecimento das indústrias ocorra. É importante salientar que muitas dessas empresas sobrevivem por mais de quarenta anos, como pode ser visualizado no quadro 1.

\section{Considerações finais}

Este estudo teve como objetivo principal analisar políticas públicas para o desenvolvimento local, tendo como base o caso de fomento e estímulo às indústrias de móveis da cidade de Guarapuava, no estado do Paraná. Assim, convém retomar algumas constatações do estudo.

Quanto às políticas do poder público municipal para a inserção de empresas moveleiras no desenvolvimento local, 
constatou-se a importância da indústria moveleira para a cidade de Guarapuava, haja vista que esse ramo de negócio está sendo alvo de políticas públicas de fomento e apoio há mais de duas décadas, ou seja, desde os anos de 1980.

A principal justificativa para a criação de políticas públicas para o setor moveleiro é o fato de existir, na cidade de Guarapuava e região, a matéria-prima principal para a produção de móveis: a madeira. Os objetivos das iniciativas públicas que se repetem a cada gestão municipal foram e são, ainda, centrados no sentido de sedimentar a produção de móveis em série e o trabalho conjunto ou cooperado entre os empresários marceneiros.

Portanto, tenta-se "converter" pequenos empresários marceneiros, que produzem móveis sob medida, em industriais, que trabalharão com o modelo de produção de móveis em série. Essa estratégia foi apontada por representantes do poder público de gestões passadas como equivocada, haja vista que não necessariamente se transformará um marceneiro em industrial devido às diferenças entre os modelos de produção e as peculiaridades de gestão e estrutura da empresa, em cada modelo, além ainda, da necessidade de altos investimentos que o modelo de produção em série exige. No entanto, essa é a estratégia atualmente adotada pelo poder público. Observe-se ainda que apenas duas indústrias atuam totalmente com o modelo de produção de móveis em série, o que significa que, de forma reiterada, as políticas públicas realizadas não geraram os resultados almejados no conjunto de empresas do setor moveleiro.

Nesse sentido, verificou-se que diversos fatores dificultaram ou dificultam a execução de iniciativas públicas para o setor moveleiro, sendo que essas dificuldades (como a falta de formação gerencial de marceneiros, barreiras políticas, cultura do modelo de produção de móveis sob medida, desunião da classe moveleira, entre outras) persistem ao longo do tempo. Observou-se que pouca ênfase foi dada a discussões de problemas e expectativas dos envolvidos no processo, sendo que, em geral, houve uma tentativa de desenhar um modelo de políticas públicas que não foi ao encontro do perfil e anseios dos pequenos empresários.
Apesar das constatações deste estudo, ainda existe, por parte do poder público, a esperança de transformar a cidade de Guarapuava num polo moveleiro, a exemplo da cidade de Arapongas, na região norte do Paraná.

\section{Referências}

ÁVILA, V.F. Pressupostos para formação educacional em desenvolvimento local. Interações - Revista Internacional de Desenvolvimento Local, Campo Grande, v. 1, n. 1, p. 63-76, set. 2000.

BARBOSA, A. F. et al. Desenvolvimento econômico e inclusão social. In: POCHMANN, M. (Org.). Reestruturação produtiva: perspectivas de desenvolvimento local com inclusão social. Petrópolis: Vozes, 2004. p. 263-321.

BARDIN, L. Análise de conteúdo. 3. ed. Lisboa: Edições 70, 2004.

BAUER, M. W.; GASKELL, G. Pesquisa qualitativa com texto, imagem e som: um manual prático. 5. ed. Petrópolis: Vozes, 2000.

BOISIER, S. Sociedad del conocimiento, conocimiento social y gestión territorial. Interações - Revista Internacional de Desenvolvimento Local, Campo Grande, v. 3, n. 3, p. 9-28, set. 2001.

Desburocratização e cidadania para o desenvolvimento local. Rio de Janeiro: IBAM/IHB/SEBRAE/FGV, 2004.

DOWBOR, L. Educação e desenvolvimento local. 2006. Disponível em: <http://dowbor.org/artigos.asp>. Acesso em: $20 \mathrm{fev} .2007$.

FERREIRA, J. Poder local e corpos intermédios. Lisboa: Edições Cultura Monárquica, 1987.

FISCHER, T. Está na hora de o Estado se fortalecer. Portal Gestão Social. 11.12.2006. Disponível em: <http:// www.gestaosocial.org.br/conteudo/noticias / entrevistas/entrevista.2007-01-04.400655 1156>. Acesso em: 06 jan. 2007.

FRANCO, A. Questões em debate. Carta Rede Social n. 106. 2006a. Disponível em: <http:/ /augustodefranco. locaweb.com.br/cartas_comments.php?id=28_0_2_0_C $>$. Acesso em: 14 jan. 2007.

FRANCO, A. O mito da política pública. Carta RedeSocial n. 126. 2006b. Disponível em: <http:// augustodefranco. locaweb.com.br/cartas_comments.php?id =55_0_2_0_C>. Acesso em: 14 jan. 2007.

GONZÁLEZ, R. R. Similitudes y diferencias de los programas de desarrollo local en Europa y América Latina. ¿Es posible establecer comparaciones? Interações - Revista Internacional de Desenvolvimento Local, Campo Grande, v. 1, n. 1, p. 07-12, set. 2000.

GUERRA, P. O município terá cada vez mais destaque nas decisões nacionais. In: PEREIRA, M. A. N. (Coord.). Proder: mudando a face dos municípios. Brasília: SEBRAE, 1997. p. 43-52.

HAIR JR. et al. Fundamentos de métodos de pesquisa em administração. Porto Alegre: Bookman, 2005. 
LOPES, R. A cidade intencional: o planejamento estratégico das cidades. 2. ed. Rio de Janeiro: 1998.

MARTINELLI, D. P.; JOYAL, A. Desenvolvimento local eo papel das pequenas e médias empresas. São Paulo: Manole, 2004.

MATA, D. O sucesso de algumas cidades. RevistaDesafios do Desenvolvimento. Ed. 22. Disponível em: <http:// www.desafios.org.br/edicoes/22/artigo177221.asp?o=r.>. Acesso em: 17 jan. 2007.

RICHARDSON, R. J. Pesquisa social: métodos e técnicas. 3. ed. São Paulo: Atlas, 1999.
SOUZA, N. J. Desenvolvimento econômico. São Paulo: Atlas, 2005.

TENÓRIO, F. G.; DUTRA, J. L. A.; MAGALHÃES, C. M. R. Gestão social e desenvolvimento local: uma perspectiva a partir da cidadania deliberativa. In ENANPAD - ENCONTRO ANUAL DA ANPAD, 2004, 28., Curitiba. Anais... Curitiba: ANPAD, 2004.

VEIGA, J. E. A face territorial do desenvolvimento. Interações - Revista Internacional de Desenvolvimento Local, Campo Grande, v. 3, n. 5, p. 5-19, set. 2002. 